\title{
Assessing sedimentological connectivity using WATEM/SEDEM model in a hilly and gully watershed of the Loess Plateau, China
}

\author{
Yu Liu ${ }^{\mathrm{a}, *}$, Bojie Fu ${ }^{\mathrm{b}}$ \\ a Key Laboratory of Ecosystem Network Observation and Modeling, Institute of Geographical Sciences and Natural Resources Research, Chinese Academy of \\ Sciences, 100101 Beijing, China \\ b State Key Laboratory of Urban and Regional Ecology, Research Center for Eco-Environmental Sciences, Chinese Academy of Sciences, 100085 Beijing, China
}

\section{A R T I C L E I N F O}

\section{Article history:}

Received 20 June 2015

Received in revised form 21 January 2016

Accepted 27 January 2016

Available online 11 February 2016

\section{Keywords:}

Landscape pattern

Landscape connectivity

Sedimentological connectivity

Soil erosion

Sediment flux

\begin{abstract}
A B S T R A C T
Sedimentological connectivity is an important issue in soil erosion and sediment transport. Landscape patterns, in combination with the rainfall regime, are known to shape such sedimentological connectivity. The quantification of sedimentological connectivity provides a link between sediment delivery and landscape pattern. There are two categories of connectivity: structural connectivity, which describes the physical coupling of landscape units, and functional connectivity, which delineates the linkage among landscape elements maintained by material transport. To quantify sedimentological connectivity, both the physical coupling of, and material transfer between, the various landscape components need to be assessed. This study quantifies the sedimentological connectivity of a headwater catchment in the Loess Plateau of China using the soil erosion and sediment delivery model (WATEM/SEDEM). Based on the model, two indicators of connectivity were developed: the area of sedimentologically effective catchment area (SEA) that contributes sediment to the sinks, and the minimum sediment output of locations on the flow path that link sources and sinks. This approach effectively represents the annual status of catchment-scale sedimentological connectivity and, furthermore, the simple structure and readily available input data make it highly practicable. However, for larger river systems in which sediment transport between sources and sinks occur over longer time scales and larger spatial scales, we suggest different techniques for quantifying the sediment flux and parameters delineating the physical coupling of landscape units.
\end{abstract}

(c) 2016 Elsevier Ltd. All rights reserved.

\section{Introduction}

In hydrologically controlled systems, sediment transport is heavily influenced by landscape patterns, such as the spatial arrangement of sediment sources, delivery pathways, and sediment sinks. Sedimentological connectivity is an effective concept to study the interrelationships between sediment transport and these factors in such a system (Brierley et al., 2006; Fryirs et al., 2007a,b; Borselli et al., 2008; Chiverrell et al., 2009).

Sedimentological connectivity refers to sediment transport from source to a sink via sediment detachment and sediment transport (Bracken and Croke, 2007; Bracken et al., 2013, 2015), and is controlled by how the sediment moves between all geomorphic zones in a landscape (Bracken et al., 2015). Sedimentological

\footnotetext{
* Corresponding author at: Key Laboratory of Ecosystem Network Observation and Modeling, Institute of Geographical Sciences and Natural Resources Research, Chinese Academy of Sciences, 100101 Beijing, China. Tel.: +86 15010466503.

E-mail address: liuyu@igsnrr.ac.cn (Y. Liu).
}

connectivity can be quantified by describing physical adjacency of landscape units (structural connectivity) or sediment transport across landscapes (functional connectivity) (Lexartza-Artza and Wainwright, 2009; Wainwright et al., 2011). While structural connectivity delineates the contiguity or physical linkage of landscape elements (With et al., 1997; Tischendorf and Fahrig, 2000), functional connectivity is indicative of the sediment flow between landscape compartments. Therefore, the physical contact status and sediment transfer among landscape compartments are some of the criteria used to categorize sedimentological connectivity (Jain and Tandon, 2010) and are the basis for measuring connectivity (Borselli et al., 2008; Heckman and Schwanghart, 2013).

Spatial arrangement of check dams, ponds and vegetation barriers effectively shapes sedimentological connectivity within a catchment, and between the catchment and the river trunks. For this reason, measuring sedimentological connectivity is used to assess the effect of landscape patterns on sediment transport. The two main approaches for quantifying connectivity include models and connectivity indices (Bracken et al., 2013). Connectivity indices are simple and easy-to-use for quantifying sedimentological 
connectivity (Imeson and Prinsen, 2004; Fryirs et al., 2007b; Borselli et al., 2008; Mayor et al., 2008). For example, the effective catchment area (EA), as defined by Fryirs et al. (2007b), is an explicit indicator of catchment connectivity. It quantifies the proportion of a catchment that potentially contributes sediment to the sinks (i.e. the river network). The identification of EA incorporates the distribution of natural or anthropogenic landscape barrier components that impede sediment movement both to and within river channels.

Based on landscape information such as land use and topographic characteristics, Borselli et al. (2008) developed the distributed index of sedimentological connectivity (IC) to quantify the probability of sedimentological linkages between sources and sinks. IC combines the probability of sediment input from upslope areas and the probability of sediment export to downward sinks. Field validation has shown that $I C$ results in a realistic spatial arrangement of sedimentological connectivity, and agrees well with field observations of sediment transfer (Borselli et al., 2008; Cavalli et al., 2013). Graph theory is also effective in assessing sedimentological connectivity and Heckman and Schwanghart (2013) explored the network structure of sediment pathways and the upslope (contributing area) and downslope (source to sink) functional connectivity. Although these quantifications of sedimentological connectivity were found to be independent of the volume of sediment flux, they represent sediment delivery risks or probability.

Physical coupling and the amount of sediment transfer between sources and sinks are the two key aspects of sedimentological connectivity (Jain and Tandon, 2010). However, the connectivity indices are mostly not involved in sediment flux quantification, and may therefore omit some meaningful information, such as the dynamic response of a system (Wainwright et al., 2011). For instance, the effective catchment area identified by Fryirs et al. (2007b) may not actually contribute runoff, and therefore sediment, to the outlet (Ambroise, 2004). Ideally, both the degree of physical coupling and the intensity of sediment transfer between a source and a sink need to be combined when measuring sedimentological connectivity. A simple and robust approach that incorporates sediment flux may provide a more realistic result. With distributed soil erosion models, such as the WATEM/SEDEM model (Van Rompaey et al., 2001), the sediment balance of each location and the sediment routing over a catchment can be quantitatively modeled. Thus, the spatially distributed models are powerful tools for the quantification of sedimentological connectivity (Jordan et al., 2005; Lesschen et al., 2009; Medeiros et al., 2010). In this approach, physical adjacency and sediment flow are combined, and structural simplicity and sediment routing capacity makes the WaTEM/SEDEM well-suited to sedimentological connectivity assessment.

In this study, we aim to develop a simple, practicable and modelbased approach to measure sedimentological connectivity on an annual average basis. According to the principles of Bracken et al. (2015), the catchment of interest (Nianzhuang of the Loess Plateau, China) is hydrologically controlled. Using WATEM/SEDEM (Van Rompaey et al., 2001; Verstraeten et al., 2002) as a foundation, two indicators are developed. These are the area of sedimentologically effective catchment area (SEA) and the minimum sediment output of sites on the flow path between source and sink (switch value, $S W$ ). Additionally, the sedimentological connectivity between hillslopes and sinks (including river channels, dam farmland and reservoirs) in a catchment in the Yellow River basin are assessed.

\section{Environmental setting}

The Nianzhuang catchment is located in the northern part of the Loess Plateau of China $\left(36^{\circ} 37^{\prime}-36^{\circ} 45^{\prime} N\right.$ N $109^{\circ} 26^{\prime}-109^{\circ} 37^{\prime}$ E, Fig. 1).
The catchment typically comprises hills and gullies with intense anthropogenic disturbance that has modified both the vegetation cover and the local landforms significantly (Fu et al., 2011; Xin et al., 2008). This catchment is a headwater of the Yellow River and has a short stream connecting it to the Yan River, a first-order tributary of the Yellow River, that covers an area of $54.2 \mathrm{~km}^{2}$. This catchment has a mean annual precipitation of $527 \mathrm{~mm}$ and has elevation ranges from 926 to $1278 \mathrm{~m}$ above mean sea level. The catchment is covered with soils of thick calcareous Cambisols (chalk loess) that evolved from loess parent material. These soils are uniformly textured, weakly structured and highly erodible by water ( $\mathrm{Li}$ et al., 2003). Well-formed gullies occur widely in Nianzhuang catchment, with a gully density of $2.74 \mathrm{~km} \mathrm{~km}^{-2}$.

In the incised valleys, check dams have been constructed to trap sediment for farming (dam farmland) or store water (reservoirs) for irrigation and fisheries (Figs. 1 and 2). More than 180 check dams have been built (Li and Bai, 2003). Cropland with a slope gradient $>25^{\circ}$ has been abandoned for revegetation. The dominant planted forest species is Robinia pseudoacacia and, elsewise, a few patches of Populus tremula and Salix alba appear in the valleys. Most shrub species are native, such as Spiraea pubescens Turcz, Rosa xanthina Lindl and Syringa oblata Lindl, and cover the northward slopes that receive relatively low solar radiation and have relatively high soil water content. Bare soil is mainly found in areas with slope gradients $>25^{\circ}$. The residential and otherwise developed areas have expanded in the valleys, especially near the catchment outlet.

Dam building and revegetation have been the main soil-loss controls in the Nianzhuang catchment. Before the 1980s, dam construction in the valleys was the primary countermeasure to reduce soil-loss (Fig. 3) and, consequently, physical coupling between hill slopes and reservoirs and dam farmland became dominant mode of landscape connectivity. Since then, revegetation has dramatically reduced sediment export from hillslopes (Liu et al., 2012). Investigation of sediment deposition in the reservoirs revealed that the soil erosion rate from 1950 to 1960 rose to $401.02 \mathrm{tha}^{-1} \mathrm{yr}^{-1}$ on average, and then decreased to $90.50 \mathrm{tha}^{-1} \mathrm{yr}^{-1}$ from 1980 to 1990 (Li and Bai, 2003).

The average soil erosion rate in rural residential areas within this catchment was $22.23 \mathrm{tha}^{-1} \mathrm{yr}^{-1}$ in 2005 , but was nearly double at $41.43 \mathrm{tha}^{-1} \mathrm{yr}^{-1}$ at the catchment-scale (Yue and Dong, 2010). The field experiment of Liu et al. (2012) on a well-vegetated hill slope inclined at $22^{\circ}$ in the Nianzhuang catchment showed that the average sediment loss was $<16 \mathrm{t} \mathrm{ha}^{-1}$ during the rainy season of 2008-2009. However, the current soil erosion rate still exceeds the regional tolerance rate of approximately $10 \mathrm{tha}^{-1} \mathrm{yr}^{-1}$ (Ministry of Water Resources of PR China, 2008).

\section{Methods}

\subsection{Model and model calibration}

In this study, the WATEM/SEDEM model is applied to model the sediment budget and consists of three components: (1) estimation of annual gross soil erosion; (2) calculation of annual transport capacity (TC); and (3) determination of sediment routing to sinks (rivers, dam farmland, reservoirs). The annual gross soil erosion (E) was estimated using the Revised Universal Soil Loss Equation (RUSLE) (Renard et al., 1997) as follows:

$E=R \times K \times L S \times C \times P$

where $E$ is the annual gross soil loss $\left(\mathrm{kg} \mathrm{m}^{-2} \mathrm{yr}^{-1}\right), R$ is the rainfall erosivity factor ( $\mathrm{MJ} \mathrm{mm} \mathrm{m} \mathrm{m}^{-2} \mathrm{~h}^{-1} \mathrm{yr}^{-1}$ ), $K$ is the soil erodibility factor $\left(\mathrm{kg} \mathrm{h} \mathrm{MJ}^{-1} \mathrm{~mm}^{-1}\right), L$ is the slope length factor (dimensionless), $S$ is the topographic slope factor (dimensionless), $C$ is the crop and management factor (dimensionless), and $P$ is the factor of erosion 


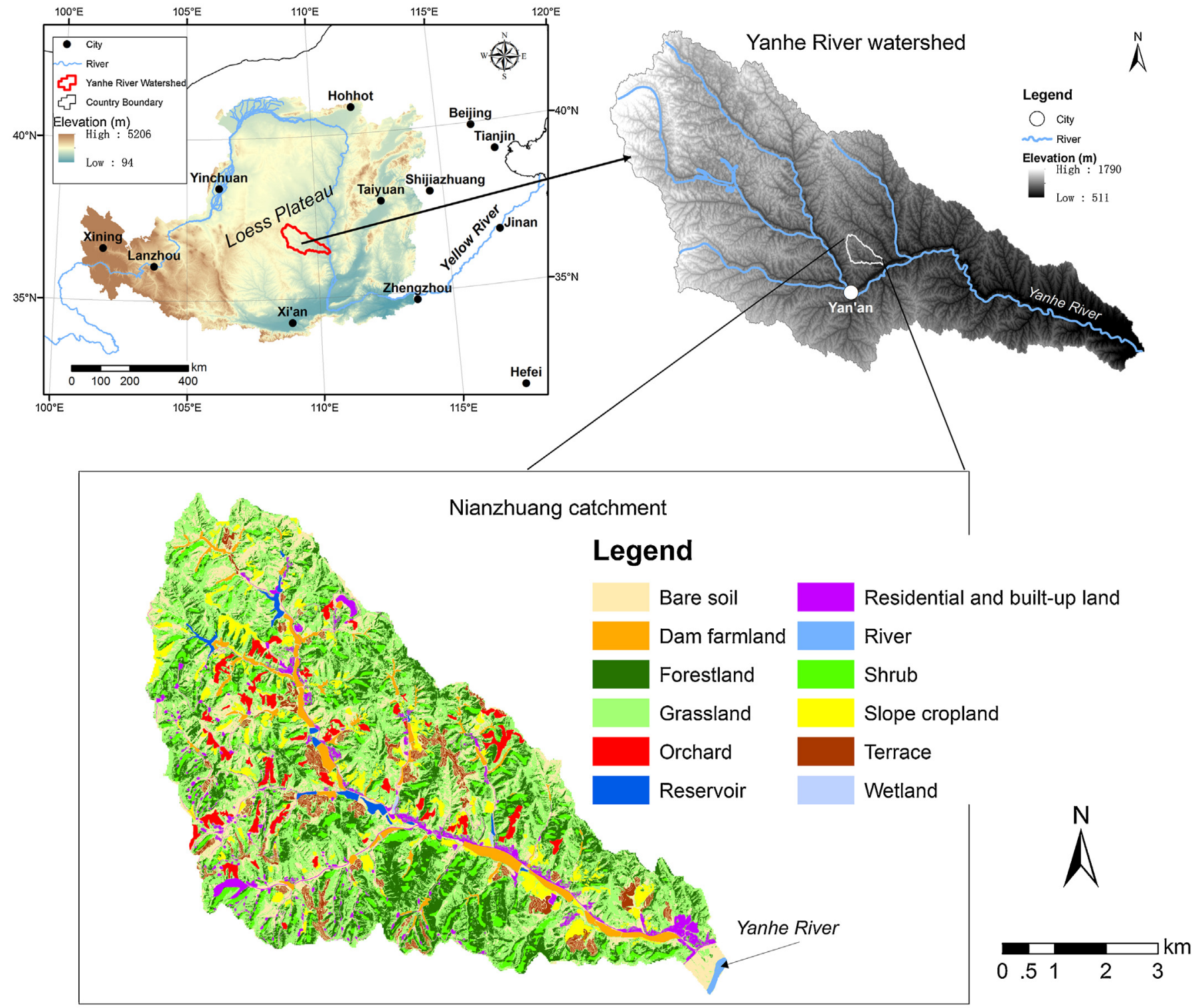

Fig. 1. Location and land cover map of the Nianzhuang catchment. Forest and grassland dominate the land cover, covering $19.69 \%$ and $36.85 \%$ of the catchment, respectively. Shrubs, bare soil, and arable land including dam farmland, slope cropland and terraced cropland account for $6.49 \%, 17.61 \%$, and $11.31 \%$ of the total catchment area, respectively. Residential and developed land comprises $3.67 \%$ of the total catchment area, while river, reservoir and wetland areas occupy $1.32 \%$ of the catchment.
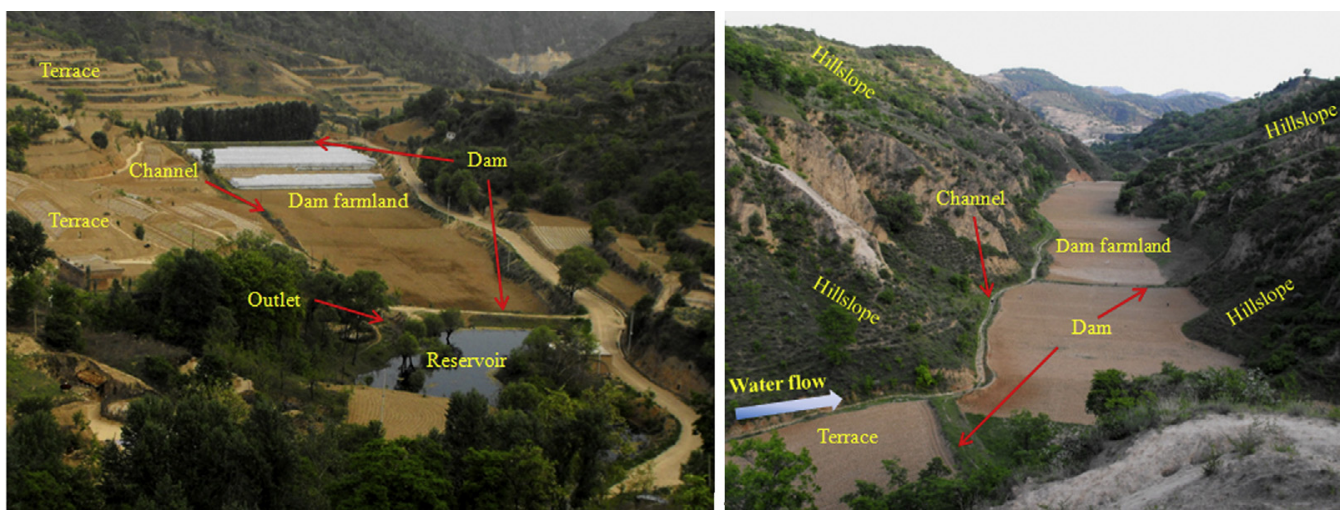

Fig. 2. Typical landscape compartments and their physical coupling pattern in the Nianzhuang catchment. Coupling between hillslopes and dam farmland and reservoirs appears to be the dominant form of landscape connectivity. 


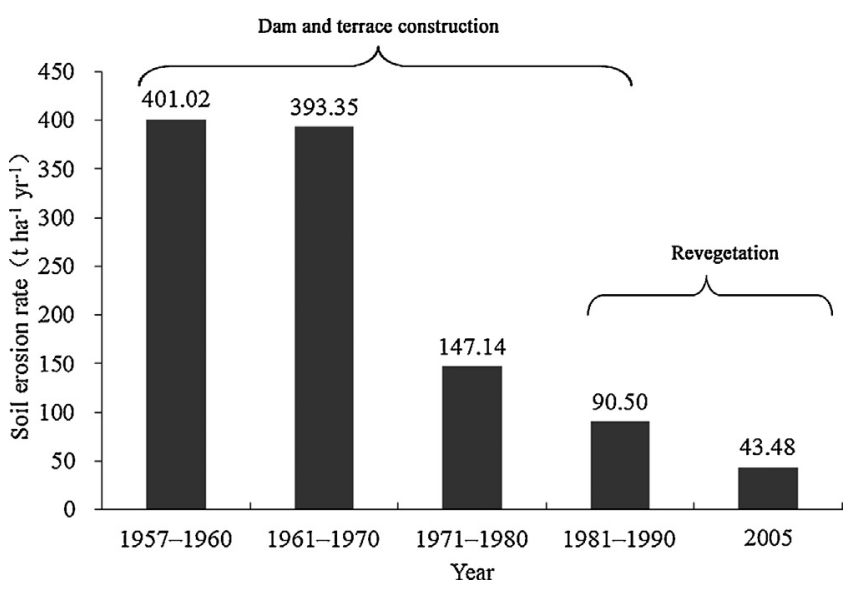

Fig. 3. Soil erosion rate and dominant soil loss prevention measures in the Nianzhuang catchment from the 1950s to 2005 (Data from Li and Bai, 2003; Yue and Dong, 2010).

control practice (dimensionless). The dimensionless combination $L S$ is the topographical factor. The value of $R$ was calculated following Wischmeier and Smith (1978). Most part of the studied catchment is covered with thick chalk loess with a uniform texture of which the $K$ value was taken as 0.02026 (Fu et al., 2005). The value of $P$ for each land cover type was obtained from Liu et al. (2001) and values of the $C$ factor were obtained from Fu et al. (2005) and Liu et al. (2001) and are shown in Table 1.

The transport capacity (TC) was estimated using Eq. (2), which incorporates the transport coefficient $\left(K_{t c}, \mathrm{~m}\right)$ of different land cover types:

$T C=K_{t c} \times R \times K\left(L S-4.12 S^{0.8}\right)$

The factor $K_{t c}$ is transport capacity coefficient. It is interpreted as the theoretical upslope distance that is needed to produce sufficient sediment to reach the local transport capacity for a uniform slope and discharge (Van Rompaey et al., 2001) and is calibrated using locally obtained data.

In the WATEM/SEDEM model, the sediment output and input of each location are modeled using the single flow-direction routing algorithm. When the available sediment supply (sediment input plus local sediment production) exceeds $T C$, the sediment output is limited to that of the TC. Otherwise, all available sediment is routed further downslope. Sediment input is equal to the sum of the sediment outputs from the adjacent areas with flow directions toward it.

Following the procedure of Van Rompaey et al. (2001), the $K_{t c}$ is calibrated using nine observed sediment yield records from seven gauged catchments on the Loess Plateau (Table 2 and Fig. 4). The

Table 1

RUSLE $C$ and $P$ factors for land use types.

\begin{tabular}{lll}
\hline Land use & Cfactor & Pfactor \\
\hline Bare soil & 1.0 & 1.0 \\
Dam farmland & 0.31 & 0.3 \\
Forest & $0.09^{*}$ & 1.0 \\
Grassland & $0.12^{*}$ & 1.0 \\
Orchard & 0.05 & 0.5 \\
Reservoir & $1.0^{*}$ & 1.0 \\
Residential and built-up land & $0.2^{*}$ & 1.0 \\
River & $1.0^{*}$ & 1.0 \\
Shrub & $0.22^{*}$ & 1.0 \\
Slope cropland & 0.55 & 0.5 \\
Terrace & 0.31 & 0.35 \\
Wetland & $0^{*}$ & 1.0 \\
\hline
\end{tabular}

* Cited from Fu et al. (2005); others referenced to Liu et al. (2001).
Table 2

Sediment yields of gauged catchments used for model calibration.

\begin{tabular}{llll}
\hline Catchment & Area (ha) & Year & Sediment yield $(\mathrm{t})$ \\
\hline Donggou & 136 & 2000 & 13.2 \\
& & 2001 & 47.3 \\
& & 2002 & 7.7 \\
Xigou & 109 & 2000 & 47.4 \\
& & 2001 & 147 \\
& & 2002 & 33.1 \\
Lvergou & 1,202 & 2001 & 14,460 \\
& & 2002 & 5,952 \\
Zaoyuan & 69,314 & 2000 & $2,047,600$ \\
Xinghe & 47,335 & 2000 & $1,160,000$ \\
Ansai & 132,582 & 2000 & $4,900,000$ \\
Ganguyu & 587,856 & 2008 & $1,300,000$ \\
\hline
\end{tabular}

land cover is reclassified as "good" (forest, grassland, and shrub) or "poor" (farmland, orchards, bare areas) as they have different sensitivities to sediment transport by overland flow. A low value of $K_{t c}\left(K_{t c}\right.$ low $)$ is thus used for good vegetation cover area, and a high value of $K_{t c}\left(K_{t c \text { high }}\right)$ for poorly vegetated areas. The model performance is evaluated by model efficiency (ME) (Nash and Sutcliffe, 1970):

$M E=1-\frac{\sum\left(Y_{o b s}-Y_{\text {pred }}\right)^{2}}{\sum\left(Y_{o b s}-Y_{\text {mean }}\right)^{2}}$

where $Y_{o b s}$ is the observed value $\left(\mathrm{ta}^{-1}\right), Y_{\text {pred }}$ the predicted value $\left(\mathrm{ta}^{-1}\right)$, and $Y_{\text {mean }}$ the mean observed sediment yield $\left(\mathrm{ta}^{-1}\right)$. The value of $M E$ can range from $-\infty$ to 1 and, the closer $M E$ is to 1 , the more efficient the model is. To obtain the correct values of $K_{t c . h i g h}$ and $K_{t c \text { _low }}$, two prerequisites are defined: (1) $K_{t c \_ \text {high }}>K_{t c \text { low }}$; and (2) the $M E$ coefficient must be the highest. For each observation, the model is executed with combinations of $K_{t c_{-} \text {low }}$ and $K_{t c_{-} \text {high }}$. Their values range from 5 to 40 in intervals of 5 . The calibrated $K_{\text {tc_high }}$ and $K_{t c \_l o w}$ are 20 and $15 \mathrm{~m}$, respectively (Fig. 5) and, with this combination, the $M E$ coefficient reaches the highest value of 0.808 .

The model accuracy is evaluated using relative root mean square error (RRMSE), as shown in Eq. (4). The calculated RRMSE is $35.52 \%$ and the modeled and observed sediment yields fit very well (Fig. 6). On the Loess Plateau, because of the weak structure of the soil, the concentration of suspended sediment in the water flow is relatively high. Verstraeten and Poesen (2001) suggested that the inaccuracy inherent in measurements of sediment yields by observing suspended sediment or sediment deposition is about 20\%. In this calibration, the corrected RRMSE is $29.35 \%$, which implies a good model performance.

RRMSE $=\frac{\sqrt{\frac{1}{n} \sum_{i=1}^{n}\left(Y_{o b s}-Y_{\text {pred }}\right)^{2}}}{\frac{1}{n} \sum_{i=1}^{n} Y_{o b s}}$

\subsection{Measurement of connectivity}

The sedimentological effective area (SEA), defined as the area that contributes sediment to the sinks, is used as an indicator of the sedimentological connectivity. A routing algorithm based on sediment output and flow direction was used to identify the SEA. Two criteria were followed to determine SEA: (1) with a flow path connected to the sinks (river channels, reservoirs and dam farmland) and (2) the sediment output of all locations on the flow path 

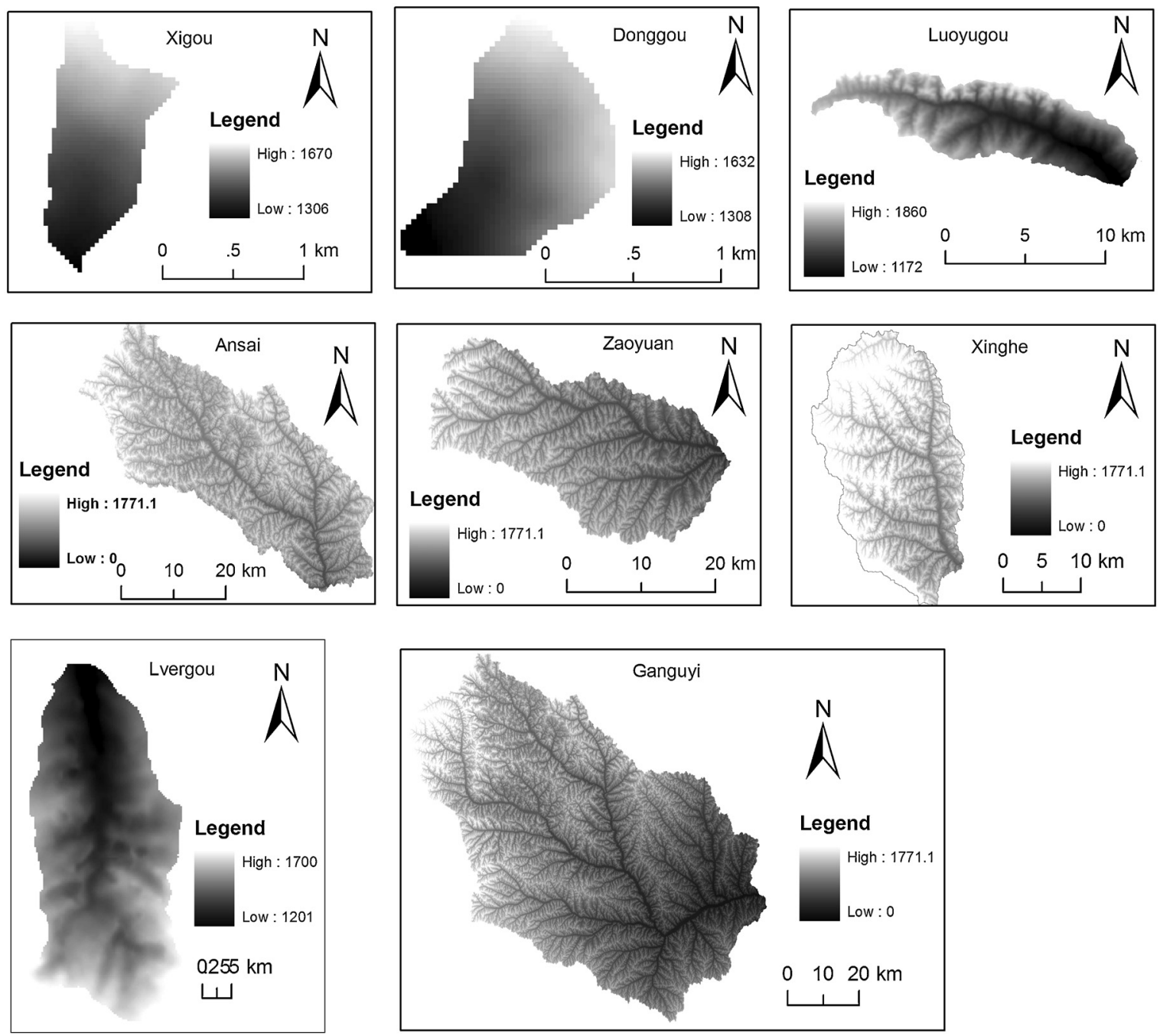

Fig. 4. Catchments with gauged sediment yields used for transport capacity coefficient $\left(K_{t c}\right)$ calibration.
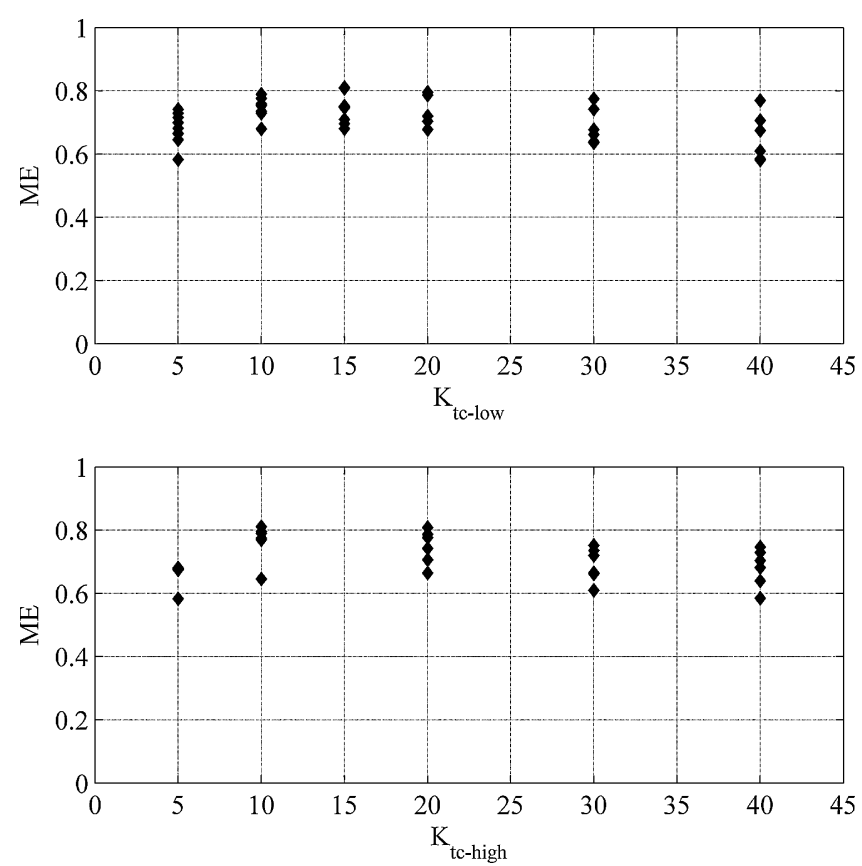

Fig. 5. Calibration of the transport capacity coefficient $\left(K_{t c}\right)$. was larger than zero. The detailed procedure used to identify the SEAs is described in the supplementary material (Fig. S1). For comparative analysis, the effective catchment area (EA) described by Fryirs et al. (2007b) was also identified. To determine the EA for dam farmland and reservoirs, rivers were considered as impedances to sediment flow. Similarly, to identify the EA for rivers, dam farmland and reservoirs were considered as impedances to sediment flow.

Another indicator of sedimentological connectivity is the degree of connection between locations and their sinks. On the flow path from a given location to a sink, the location with the minimum sediment output (switch location) plays a switching role. It limits the sediment flux. Therefore, the degree of connection is quantified by the sediment output of the switch location (the switch value, $S W$ ) where locations with $S W=0$ being regarded as sedimentologically disconnected with the sink. The detail procedure employed to compute the switch value of locations in an SEA is described in the supplementary material (Fig. S2).

Additionally, the connectivity of a location to upslope areas is quantified by the sediment input whereby the higher the sediment input, the greater the connectivity. Thus, the connectivity depends on the topographical pattern, spatial pattern of rainfall, pattern of soil erodibility, land cover pattern and soil conservation practices. Connectivity measured in this way has the potential to indicate the impact of landscape pattern on sediment flux. 


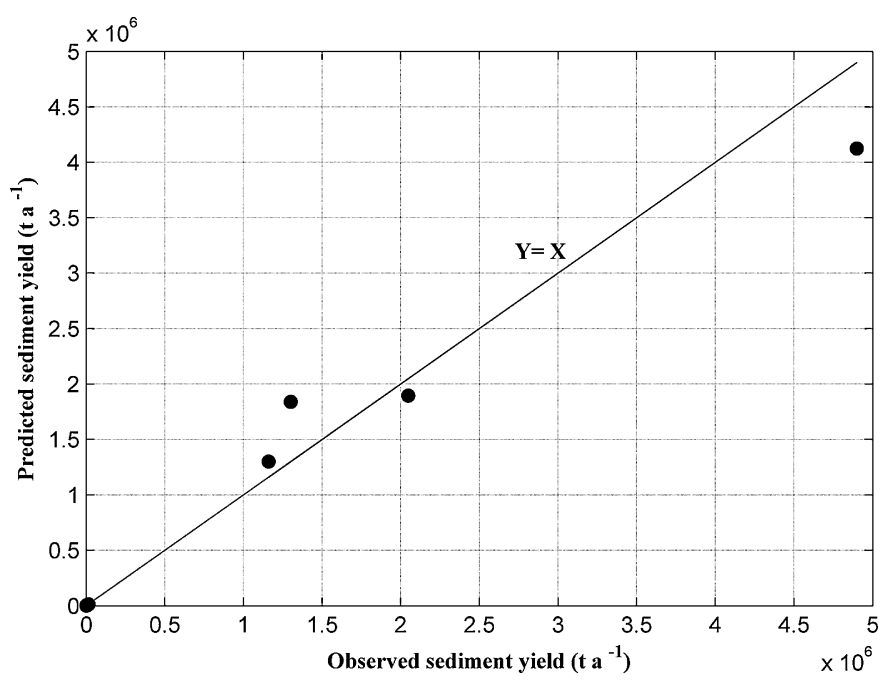

Fig. 6. Observed vs. modeled sediment yield $\left(\mathrm{ta}^{-1}\right)$.

\subsection{Data sources and analysis}

The land cover map of the Nianzhuang catchment in 2006 was interpreted by combining the Alos PRISM and AVNIR-2 images with spatial resolutions of $2.5 \mathrm{~m}$ and $10 \mathrm{~m}$, respectively. Erdas 2010 (Leica Geosystems Geospatial Imaging, LLC, GA, USA) was used as the mapping platform. A digital elevation model (DEM) of $10 \mathrm{~m} \times 10 \mathrm{~m}$ resolution derived from a 1:10,000 topographical map was used. Daily rainfall data of the nearest weather station (Yan An, Shannxi Province), was used in calculating rainfall erosivity. The measurement of connectivity was conducted using Arc/info 8.1 (Environmental Systems Research Institute Inc., California, USA) with a program in Arc Macro Language (AML).

\section{Results}

\subsection{Catchment sediment flux}

The modeled mean soil erosion rate of the Nianzhuang catchment was $18.15 \mathrm{tha}^{-1} \mathrm{yr}^{-1}$, with gross annual soil erosion of $99,237 \mathrm{t}$ in 2006. Mean sediment input and output were 18.22 $\mathrm{tha}^{-1} \mathrm{yr}^{-1}$ and $19.40 \mathrm{tha}^{-1} \mathrm{yr}^{-1}$, respectively. Of the total catchment area, $73.3 \%$ has a soil erosion rate $<10 \mathrm{tha}^{-1} \mathrm{yr}^{-1}$, with the remaining $26.7 \%$ being $>10 \mathrm{tha}^{-1} \mathrm{yr}^{-1}$. The former contributed $13 \%$ to the gross soil erosion of the catchment, while the latter accounted for $87 \%$. Areas with high soil erosion rates were found to be mainly located near the dam farmland, reservoirs and rivers. They were the main contributors of sediment to these sinks (Fig. 7). The mean sediment output of the SEA was $37.94 \mathrm{tha}^{-1} \mathrm{yr}^{-1}$ for dams and reservoirs, and $35.81 \mathrm{tha}^{-1} \mathrm{yr}^{-1}$ for rivers.

The results show that topographical ponds, vegetation barriers and buffers effectively impede sediment flux to the various sinks, and only a small fraction of the gross soil erosion within the catchment was delivered to these sinks. The total sediment discharged into these sinks was $1020 \mathrm{t}$, of which $892 \mathrm{t}$ was trapped by dam farmland and reservoirs, and $128 \mathrm{t}$ was exported into the rivers. At the catchment scale, the sediment delivery ratio was 0.01 .

In this study, source areas refer to those locations with higher sediment output than input and, if the sediment input exceeds output, the location is identified as a sink. If sediment input and output are equal, the location is recognized as neutral. The results imply that the sediment generated in most areas of the catchment do not reach the sinks. In addition to the dam farmland, reservoirs and rivers, some areas of the hillslopes might also function as sediment sinks because of vegetation cover or topographical characteristics. Although the vegetated areas (grassland, forest, shrub land) occupy $63 \%$ of the catchment area, most of the hillslope areas have higher sediment outputs than inputs (Fig. 8).
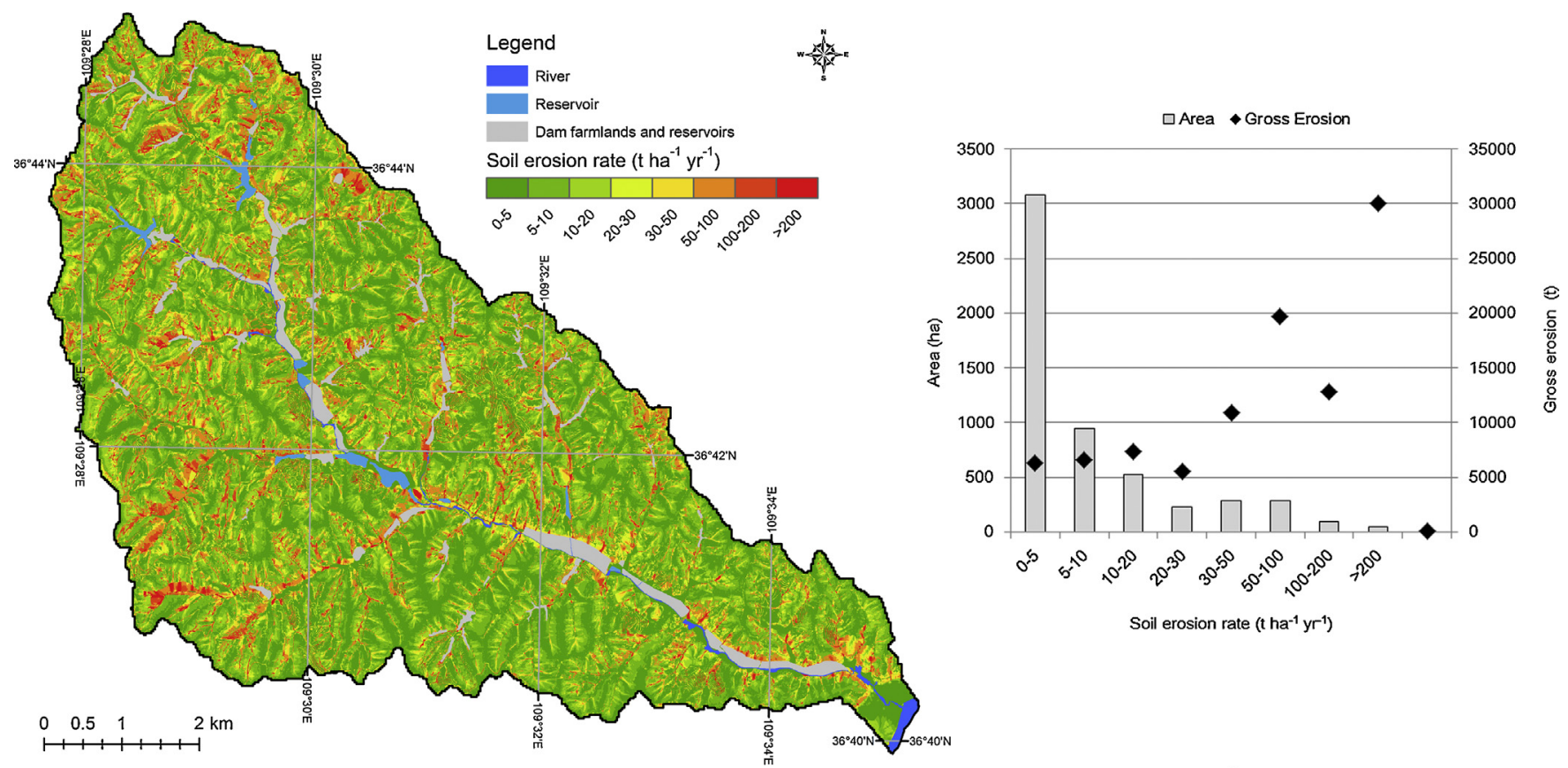

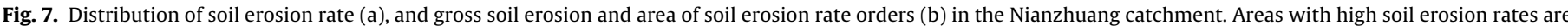

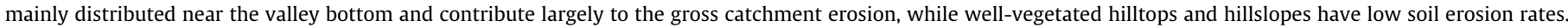
Areas with greater soil erosion rate are the greater contributors of the gross soil erosion. 


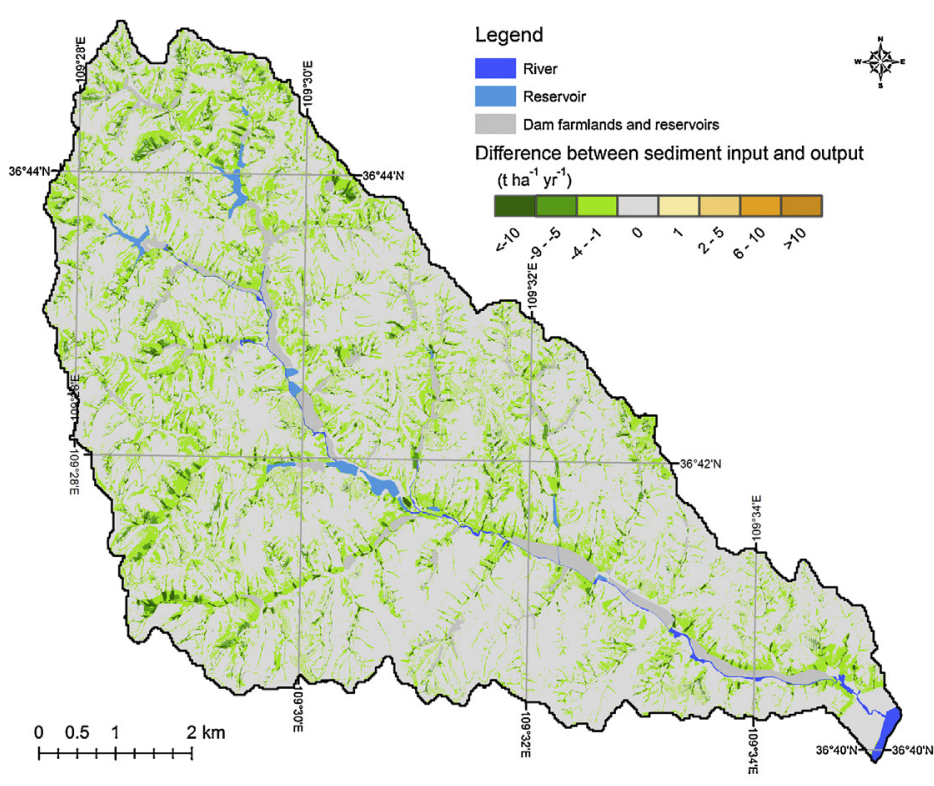

a

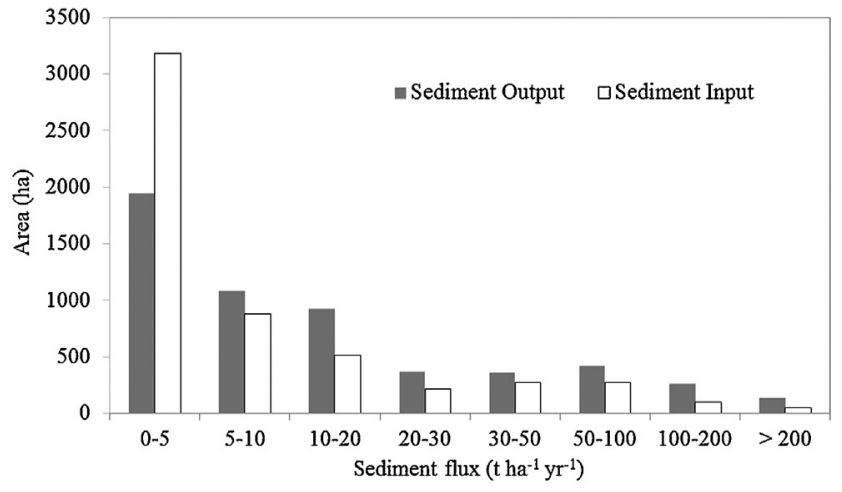

b

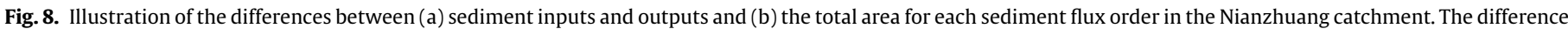

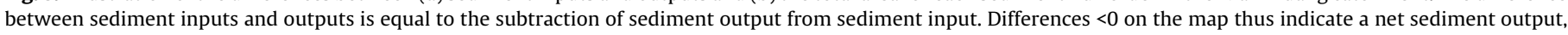
areas with differences $\approx 0$ indicate an input/output balance and areas of net deposition are consistent with sediment differences $>0$.

\subsection{Catchment connectivity}

The estimated area of SEA for rivers was $8.39 \mathrm{~km}^{2}$ and that for dam farmland and reservoirs was $43.96 \mathrm{~km}^{2}$. This accounts for $15.5 \%$ and $80.3 \%$ of the catchment area, respectively. The estimated area of EA, following the method of Fryirs et al. (2007b), was $8.85 \mathrm{~km}^{2}$ for rivers and $46.22 \mathrm{~km}^{2}$ for dam farmland and reservoirs. These results reveal that some areas judged as contributors of sediment to the sinks from a structural perspective of connectivity, might not be contributors when considering the sediment flux (Fig. 9), especially over short time scales. This was confirmed by the spatial pattern of $S W$ (Fig. 9). A mean $S W$ value of $3.57 \mathrm{tha}^{-1} \mathrm{yr}^{-1}$ was determined for sediment source areas of river channels, but a value of $3.25 \mathrm{tha}^{-1} \mathrm{yr}^{-1}$ was determined for reservoirs and dam farmland. It is evident that areas close to sinks and with a steep slope gradient have high sedimentological connectivity to sinks, and are the main sediment contributors (Fig. 9). It is notable that the switch values were rather low in comparison with the mean sediment output of the SEAs for sinks (Fig. 10).

With a longer flow path to the sinks, there is a higher probability that sediment will be trapped by impedances (Kirkby, 2001; Kirkby et al., 2002; Blanco-Canqui et al., 2004; Rey, 2004) and, therefore, the SEAs close to sinks contribute more sediment. As illustrated by the distribution of $S W$ (Fig. 11), most areas with high sediment outputs have short flow paths and high $S W$ - indicating a high probability of sediment transfer to the sinks from these areas.

\section{Discussion}

\subsection{Model performance}

The approach developed in this study integrates both the structural connectivity and functional connectivity. It enhances availability of the concept of sedimentological connectivity for catchment management, arrangement of soil loss prevention infrastructure and watershed hazard countermeasures. Where data are limited, sedimentological connectivity measured from the perspective of physical coupling provides a simple and fast solution for qualitatively identifying sediment contribute areas, and the critical areas for soil erosion and sediment flux control. However, sedimentological connectivity not only refers to the connectivity of sediment source to sinks through flow pathways, but also is concerned with the magnitude of sediment flux on the pathway. As shown in this study, the sediment source areas of specific sinks, including outlets or other locations considered, can be identified. Meanwhile, based on the modeling of sediment inputs and outputs of each location, the degree of connection between the sources and sinks can be quantified.

Compared with models that have greater physical basis such as Geowepp (Renschler, 2003), the lower demand for data input and simpler structure make WATEM/SEDEM easier to use. More importantly, modeling the sediment flux across each location enables the evaluation of the effects of different land use scenarios and soil conservation techniques (Van Rompaey et al., 2001). However, soil erosion modeling in WaTEM/SEDEM is not physically based, thus potentially limiting the efficiency of the model output. The model efficiency was considered unsatisfactory when validated using distributed data obtained by the ${ }^{137}$ Cs trace method (Feng et al., 2010) because it showed that the model underestimates the actual sitespecific soil loss. This underestimation can be attributed partly to the dominance of gully erosion in this region (Li et al., 2003), although it must be understood that modeling of gully and channel flow erosion, as well as gravitational erosion, are not included in the WATEM/SEDEM model.

Although the model calibration of Feng et al. (2010) using spatially distributed data revealed that WATEM/SEDEM underestimated soil loss, it can still reliably predict the spatial pattern of soil loss. Therefore, the incorporation of this model into measuring sedimentological connectivity is meaningful from the perspective of methodology, especially for the evaluation of the impact of landscape patterns. To improve modeling efficiency, spatially distributed models driven by spatially distributed input data are needed to model as many of the erosive processes as possible. However, this is a considerable challenge regarding the model design and the collection of spatially distributed data for the running and calibration of the model. 

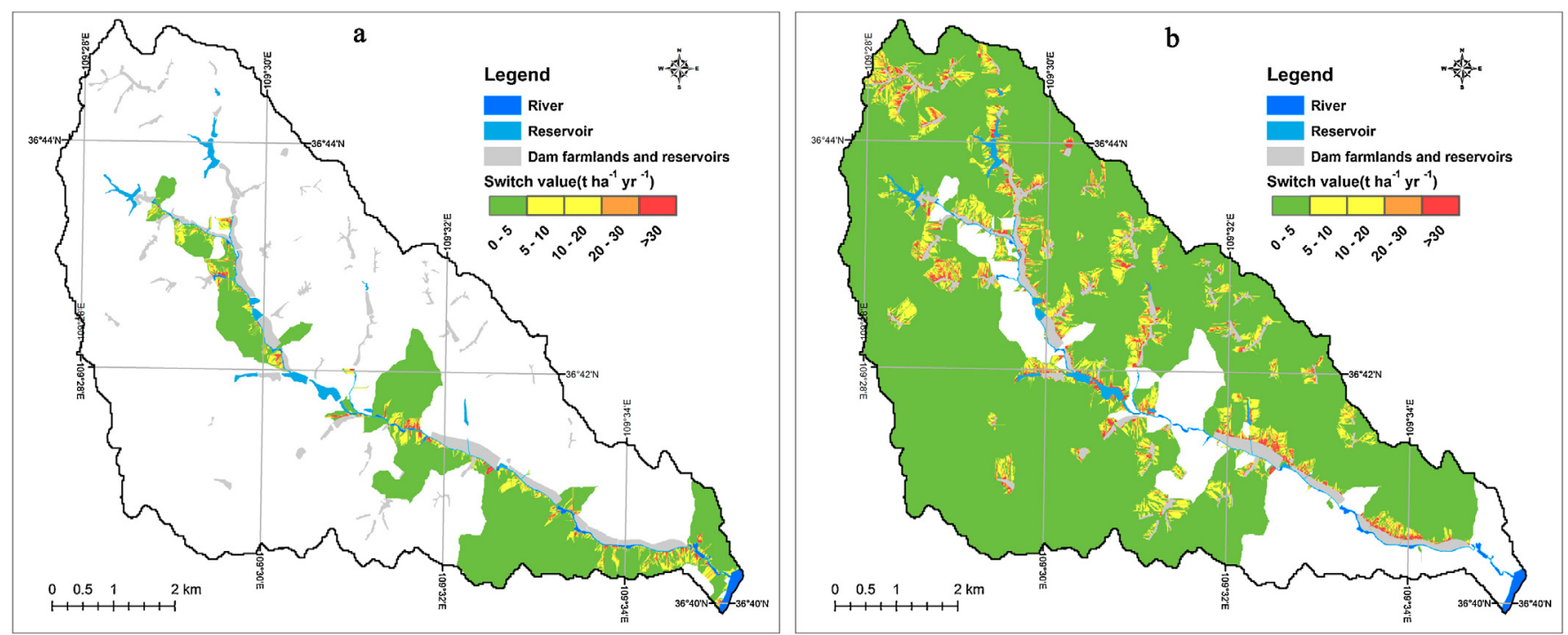

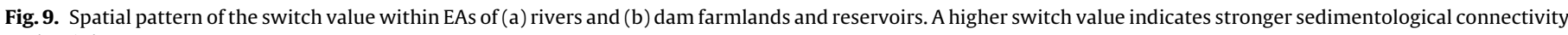
to the sinks.
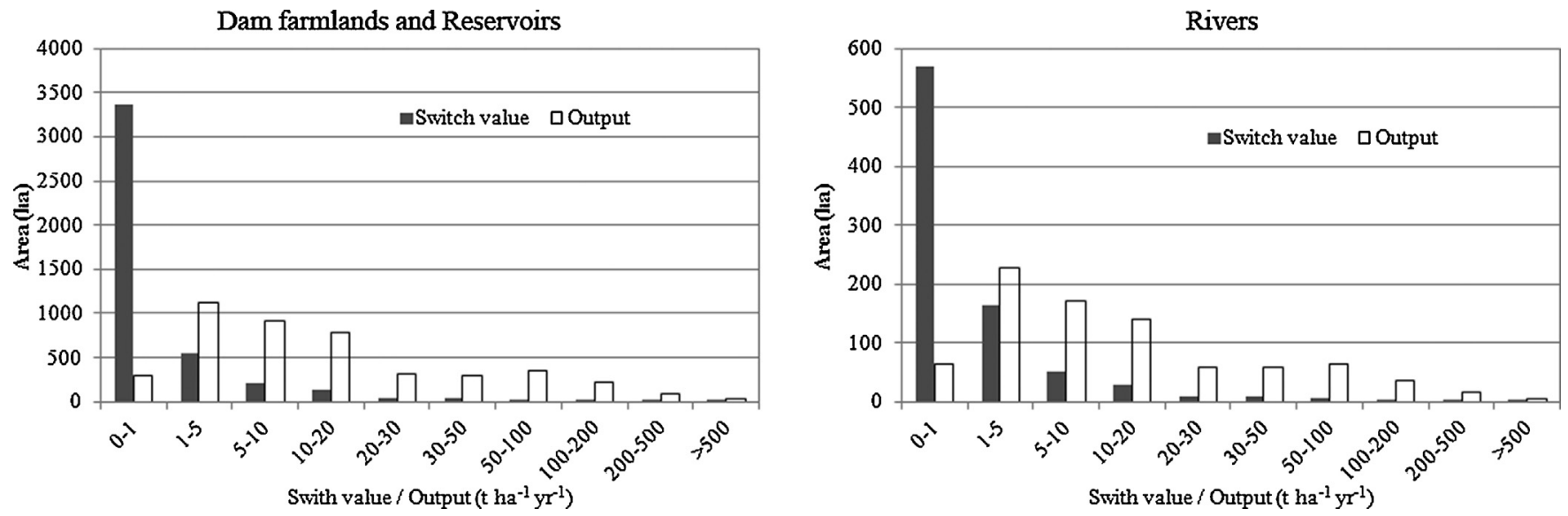

Fig. 10. Areal distribution of sediment outputs and switch values for the two types of sinks.
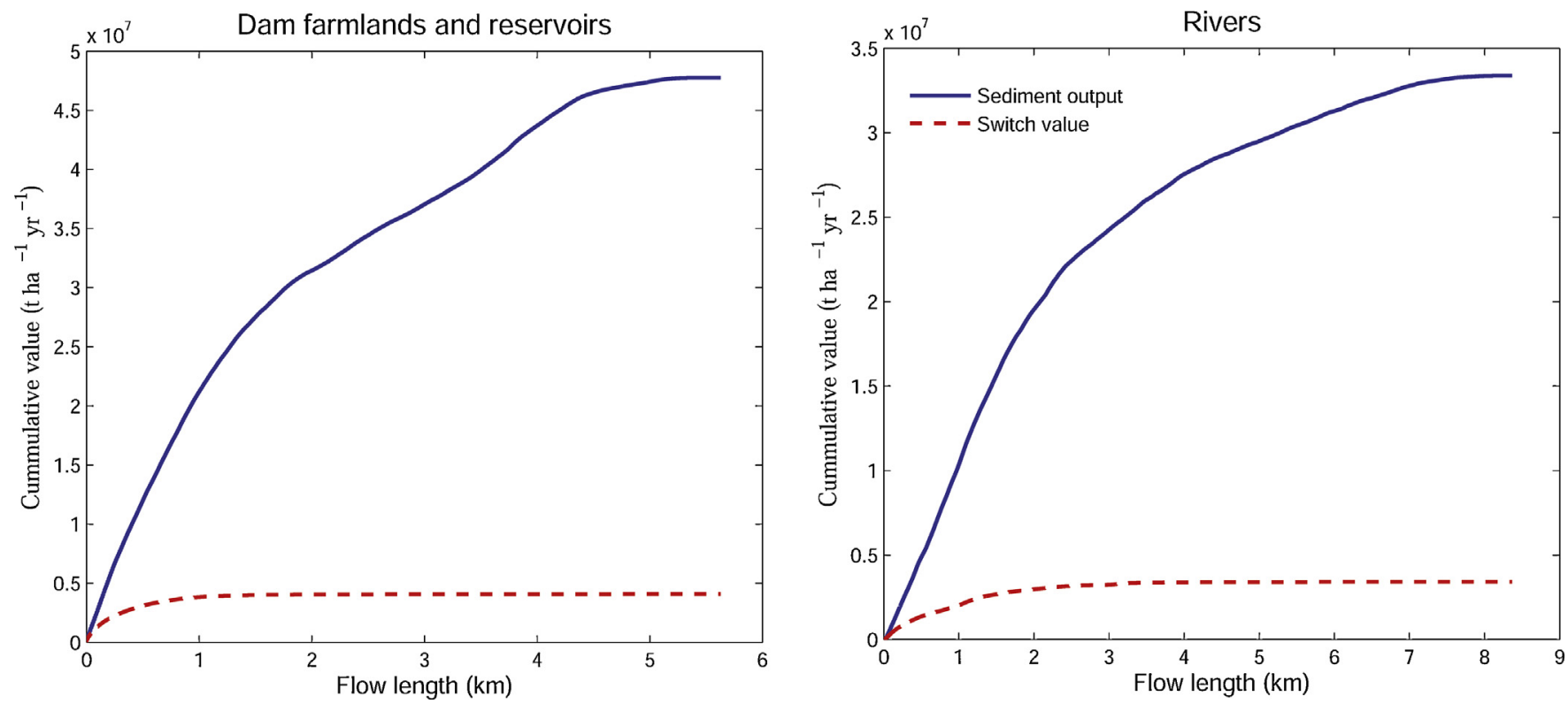

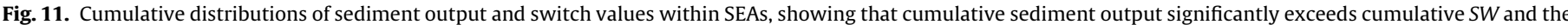
accumulation of $S W$ approaches a constant value within a short flow path length. 


\subsection{Model application prospects}

Integrating structural and functional connectivity provides the potential to assess the effects of landscape patterns on sediment flux. As a case study, the headwater catchments of the Loess Plateau appear to be the main contributors to the high concentration of sediment in the Yellow River (Xu and Cheng, 2002; Liu et al., 2008). Anthropogenic activities, such as revegetation, check-dam construction, and the development of terraced farmland, have caused considerable shifts in the landscape pattern (Wang et al., 2007; Xin et al., 2008) and low sediment export to the sinks of the Nianzhuang catchment shows that landscape patterns effectively control sediment discharge. Thus, such activities ultimately cut-off or weaken sedimentological connectivity.

Xu and Cheng (2002) concluded that sediment production from the coarse-sediment producing area of the Yellow River, which is part of the Loess Plateau, contributes considerably to the sediment flux of the Yellow River. However, because of anthropogenic intervention (dam construction, revegetation) the sediment fluxes from the headwater catchments to the Yellow River have been cut-off or limited, as has been shown in this study. Thus, the distribution of the sediment source areas of the Yellow River may shrink significantly. Thanks to its sediment transport routing capacity, the WATEM/SEDEM model has the potential to detect the impact of land cover patterns on the sedimentological connectivity and, using the approach outlined in this study, the spatial distribution of sediment contribution of source areas can be modeled. For example, the tremendous decrease in sediment flux within the context of an insignificant decrease in rainfall over the middle section of the Yellow River (Liu et al., 2008) can be explained using this approach.

\subsection{Scale issues}

Sedimentological connectivity varies according to spatial and temporal scales over which the process operates. Four sedimentological connectivities can be recognized depending on the temporal and spatial scale: (1) short time and small space connectivity; (2) long time and large space connectivity; (3) short time and large space connectivity; and (4) long time and small space connectivity (Jain and Tandon, 2010). In this study, the catchment area is considered to be small $\left(54.2 \mathrm{~km}^{2}\right)$ and intense storms are one of the main contributors to the variation in the rate of soil erosion (Jiao et al., 1999). Thus, the approach developed in this study uses WATEM/SEDEM as a sediment modeling tool is on an annual scale, but cannot reflect the highly dynamic sedimentological connectivity at a higher temporal resolution. However, the simplicity makes it practicable for a catchment like the Nianzhuang catchment in which a quantitative image of the rainfall-runoff caused by catchment sedimentological connectivity can be obtained, along with integration of the amount of sediment and physical linkages between source and sink. Additionally, this approach has the potential to be revised for different temporal scales by replacing WATEM/SEDEM with other spatially distributed model.

For a larger area, such as the Ganga River system (Jain and Tandon, 2010), the sedimentological connectivity between the source areas (mountainous area) and sinks (rivers or oceans) not only involves coupling between hillslopes and channels, but also many other forms, such as between tributaries, floodplains and river trunks. Sediment transport is also likely to occur at only a low frequency. Thus, the connectivity would need to be assessed over longer temporal scales and the sediment delivery quantification method might be different from this study in terms of data support and computation capacity. Methods such as isotope tracing (Polyakov et al., 2009; Barthold et al., 2010; Jain and Tandon, 2010; Willenbring and Blanckenburg, 2010) might prove a better choice, as well as a geomorphic or spatial pattern approach with geomorphic parameters to delineate connectivity without concern for the sediment flow over each location (Ibrahim, 2005).

\section{Conclusions}

To assess sedimentological connectivity in the Nianzhuang catchment of the Loess Plateau, China, an approach was developed that incorporates a spatially distributed sediment delivery model (WATEM/SEDEM). Two indicators were used to quantitatively delineate the catchment connectivity, namely the area of sedimentologically effective catchment area (SEA) and the switch value $(S W)$. The former is a measure of the area that contributes sediment to sediment sinks, while the latter quantifies the degree of (or intensity of) sedimentological connectivity between sources and sinks.

The estimated SEA of the Nianzhuang catchment was found to be $8.39 \mathrm{~km}^{2}$ for rivers and $43.96 \mathrm{~km}^{2}$ for dam farmland and reservoirs, thus accounting for $15.5 \%$ and $80.3 \%$ of the catchment area, respectively. The switch value proved to be a good measure with which to interpret the low sediment delivery ratio at the catchment level because it was found that, despite the on-site soil erosion rate being relatively high, only a small fraction of the sediment was transported to the sinks.

The approach developed in this study has the potential for use in assessing the impact of landscape patterns on catchment sedimentological connectivity. It is structurally simple and technically available. However, for a larger scale, the approach to obtain the required sediment flow data needs adjustment. Furthermore, soil erosion processes, such as gully erosion, channel erosion and gravitational erosion, were not included in the WATEM/SEDEM model. It may be helpful in future to include various erosion processes in such modeling and spatially distributed input data for calibration/validation.

\section{Acknowledgments}

This work was supported by the National Natural Science Foundation of China (Grant Nos. 41390464 and 41301032). We thank two anonymous reviewers for their constructive comments and suggestions.

\section{Appendix A. Supplementary data}

Supplementary data associated with this article can be found, in the online version, at http://dx.doi.org/10.1016/j.ecolind.2016. 01.055 .

\section{References}

Ambroise, B., 2004. Variable ‘active’ versus ‘contributing' areas or periods: a necessary distinction. Hydrol. Process 18, 1149-1155.

Barthold, F.K., Wu, J.K., Vaché, K.B., Schneider, K., Frede, H., Breuer, L., 2010. Identification of geographic runoff sources in a data sparse region: hydrological processes and the limitations of tracer-based approaches. Hydrol. Process 24, 2313-2327.

Blanco-Canqui, H., Gantzer, C.J., Anderson, S.H., Alberts, E.E., Thompson, A.L., 2004. Grass barrier and vegetative filter strip effectiveness in reducing runoff, sediment, nitrogen, and phosphorus loss. Soil Sci. Soc. Am. J. 68, 1670-1678.

Borselli, L., Cassi, P., Torri, D., 2008. Prolegomena to sediment and flow connectivity in the landscape: a GIS and field numerical assessment. Catena 75, 268-277.

Bracken, L.J., Croke, J., 2007. The concept of hydrological connectivity and its contribution to understanding runoff-dominated geomorphic systems. Hydrol. Process 21, 1749-1763.

Bracken, L.J., Turnbull, L., Wainwright, J., Bogaart, P., 2015. Sediment connectivity: a framework for understanding sediment transfer at multiple scales. Earth Surf. Process. Landf. 40, 177-188.

Bracken, L.J., Wainwright, J., Ali, G.A., Tetzlaff, D., Smith, M.W., Reaney, S.M., Roy, A.G., 2013. Concepts of hydrological connectivity: research approaches, pathways and future agendas. Earth Sci. Rev. 119, 17-34

Brierley, G., Fryirs, K., Jain, V., 2006. Landscape connectivity: the geographic basis of geomorphic applications. Area 38 (2), 165-174. 
Cavalli, M., Trevisani, S., Comiti, F., Marchi, L., 2013. Geomorphometric assessment of spatial sediment connectivity in small Alpine catchments. Geomorphology $188,31-41$.

Chiverrell, R.C., Foster, G.C., Marshall, P., Harvey, A.M., Thomas, G.S.P., 2009. Coupling relationships: hillslope-fluvial linkages in the Hodder catchment, NW England. Geomorphology 109, 222-235.

Feng, X.M., Wang, Y.F., Chen, L.D., Fu, B.J., Bai, G.S., 2010. Modeling soil erosion and its response to land-use change in hilly catchments of the Chinese Loess Plateau. Geomorphology 118, 239-248.

Fryirs, K.A., Brierley, G.J., Preston, N.J., Kasai, M., 2007a. Buffers, barriers and blankets: the (dis)connectivity of catchment-scale sediment cascades. Catena 70, 49-67.

Fryirs, K.A., Brierley, G.J., Preston, N.J., Spencer, J., 2007b. Catchment-scale (dis)connectivity in sediment flux in the upper Hunter catchment, New South Wales, Australia. Geomorphology 84, 297-316.

Fu, B.J., Zhao, W.W., Chen, L.D., Zhang, Q.J., Lu, Y.H., Gulinck, H., Poesen, J., 2005. Assessment of soil erosion at large watershed scale using RUSLE and GIS: A case study in the Loess Plateau of China. Land Degrad. Dev. 16, 73-85.

Fu, B., Liu, Y., Lü, Y., He, C., Zeng, Y., Wu, B., 2011. Assessing the soil erosion control service of ecosystems change in the Loess Plateau of China. Ecol. Complex. 8, 284-293.

Heckman, T., Schwanghart, W., 2013. Geomorphic coupling and sediment connectivity in an alpine catchment - exploring sediment cascades using graph theory. Geomorphology 182, 89-103.

Ibrahim, E.A.H., (Ph.D. thesis) 2005. Analyzing the connectivity potential of landscape geomorphic systems: a radar remote sensing and GIS approach. Estufa Canyon, Texas, USA. Geology \& Geophysics Department, Texas A\&M University, College Station, Texas, USA.

Imeson, A.C., Prinsen, H.A.M., 2004. Vegetation patterns as biological indicators for identifying runoff and sediment source and sink areas for semi-arid landscapes in Spain. Agric. Ecosyst. Environ. 104, 333-342.

Jain, V., Tandon, S.K., 2010. Conceptual assessment of (dis)connectivity and its application to the Ganga River dispersal system. Geomorphology 118, 349-358.

Jiao, J., Wang, W., Hao, X., 1999. Precipitation and erosion characteristics of rainstorm in different pattern on Loess Plateau. J. Arid Land Resour. Environ. 13, 34-42 (in Chinese).

Jordan, G., van Rompaey, A., Szilassi, P., Csillag, G., Mannaerts, C., Woldai, T., 2005. Historical land use changes and their impact on sediment fluxes in the Balaton basin (Hungary). Agric. Ecosyst. Environ. 108, 119-133.

Kirkby, M., 2001. Modelling the interactions between soil surface properties and water erosion. Catena 46, 89-102.

Kirkby, M., Bracken, L., Reaney, S., 2002. The influence of land use, soils and topography on the delivery of hillslope runoff to channels in SE Spain. Earth Surf. Process. Landf. 27, 1459-1473.

Lesschen, J.P., Schoorl, J.M., Cammeraat, L.H., 2009. Modelling runoff and erosion for a semi-arid catchment using a multi-scale approach based on hydrological connectivity. Geomorphology 109, 174-183.

Lexartza-Artza, I., Wainwright, J., 2009. Hydrological connectivity: linking concepts with practical implications. Catena 79, 146-152.

Li, Y., Bai, L.Y., 2003. Variation of sediment and organic carbon storage by check-dams of Chinese Loess Plateau. J. Soil Water Conserv. 17, 1-19 (in Chinese).

Li, Y., Poesen, J., Yang, J.C., Fu, B., Zhang, J.H., 2003. Evaluating gully erosion using Cs-137 and Pb-210/Cs-137 ratio in a reservoir catchment. Soil Tillage Res. 69, 107-115.

Liu, B., Xie, Y., Zhang, K.L., 2001. Soil Loss Prediction Models. Chinese Science and Technology Press, Beijing (in Chinese)

Liu, C., Sui, J., Wang, Z.Y., 2008. Changes in Runoff and Sediment Yield along the Yellow River during the Period from 1950 to 2006. J. Environ. Inf. 12, 129-139.
Liu, Y., Fu, B., Lü, Y., Wang, Z., Gao, G., 2012. Hydrological responses and soil erosion potential of abandoned cropland in the Loess Plateau, China. Geomorphology 138, 404-414.

Mayor, Á.G., Bautista, S., Small, E.E., Dixon, M., Bellot, J., 2008. Measurement of the connectivity of runoff source areas as determined by vegetation pattern and topography: a tool for assessing potential water and soil losses in drylands. Water Resour. Res. 44, W10423, http://dx.doi.org/10.1029/2007WR006367.

Medeiros, P.H.A., Guntner, A., Francke, T., Mamede, G.L., de Araújo, J.C., 2010. Modelling spatio-temporal patterns of sediment yield and connectivity in a semi-arid catchment with the WASA-SED model. Hydrol. Sci. J. 55, 636-648.

Ministry of Water Resources of PR China, 2008. Standard for Classification and Gradation of Soil Erosion SL 190-2007. China Waterpower Press, Beijing, China (in Chinese).

Nash, J.E., Sutcliffe, J.V., 1970. River flow forecasting through conceptual models: Part 1. A discussion of principles. J. Hydrol. 10, 282-290.

Polyakov, V.O., Kimoto, A., Nearing, M.A., Nichols, M.H., 2009. Tracing sedimen movement on a semiarid watershed using rare earth elements. Soil Sci. Soc. Am. J. 73, 1559-1565.

Renard, K.G., Foster, G.R., Weesies, G.A., McCool, D.K., Yoder, D.C., 1997. Predicting soil erosion by water: a guide to conservation planning with the revised universal soil loss equation (RUSLE). USDA Agriculture Handbook 703.

Renschler, C.S., 2003. Designing geo-spatial interfaces to scale process models: the GeoWEPP approach. Hydrol. Process 17, 1005-1017.

Rey, F., 2004. Effectiveness of vegetation barriers for marly sediment trapping. Earth Surf, Process. Landf. 29, 1161-1169.

Tischendorf, L., Fahrig, L., 2000. How should we measure landscape connectivity? Landsc. Ecol. 15, 633-641.

Van Rompaey, A.J., Sahlin, J., Verstraeten, G., Van Oost, K., Govers, G., Poesen, J., 2001 Modelling mean annual sediment yield using a distributed approach. Earth Surf. Process. Landf. 26, 1221-1236.

Verstraeten, G., Poesen, J., 2001. Factors controlling sediment yield from small intensively cultivated catchments in a temperate humid climate. Geomorphology 40 (1-2), 123-144.

Verstraeten, G., Van Oost, K., Van Rompaey, A., Poesen, J., Govers, G., 2002. Evaluating an integrated approach to catchment management to reduce soil loss and sediment pollution through modelling. Soil Use Manag. 18, 386-394.

Wainwright, J., Turnbull, L., Ibrahim, T.G., Lexartza-Artza, I., Thornton, S.F., Brazier, R.E., 2011. Linking environmental régimes, space and time: Interpretation of structural and functional connectivity. Geomorphology 126, 387-404.

Wang, H.J., Yang, Z.S., Saito, Y., Liu, J.P., Sun, X.X., Wang, Y., 2007. Stepwise decreases of the Huanghe (Yellow River) sediment load (1950-2005): impacts of climate change and human activities. Glob. Planet. Change 57, 331-354.

Willenbring, J.K., Blanckenburg, F.V., 2010. Long-term stability of global erosion rates and weathering during late-Cenozoic cooling. Nature 465, 211-214.

Wischmeier, W.H., Smith, D.D., 1978. Predicting Rainfall Erosion Losses: a guide to conservation planning. USDA Agricultural Research Services Handbook, vol. 537 USDA, Washington, DC, pp. 57.

With, K.A., Gardner, R.H., Turner, M.G., 1997. Landscape connectivity and population distributions in heterogeneous environments. Oikos 78, 151-169.

Xin, Z.B., Xu, J.X., Zheng, W., 2008. Spatiotemporal variations of vegetation cover on the Chinese Loess Plateau (1981-2006): impacts of climate changes and human activities. Sci. China Ser. D 51, 67-78.

Xu, J.X., Cheng, D.S., 2002. Relation between the erosion and sedimentation zones in the Yellow River, China. Geomorphology 48, 365-382.

Yue, D.P., Dong, M.Y., 2010. Investigation and estimation of soil Erosion of rura settlements in abundant and coarse sediment area of north Shaanxi - an example in Nianzhuanggou river basin. J. Catastrophol. 25 (1), 59-63 (in Chinese). 